\title{
Ingestion of sweet water enhances the rewarding effect of morphine in rats
}

\author{
BOW TONG LETT \\ Memorial University of Newfoundland, St. John's, Newfoundland, Canada
}

\begin{abstract}
Exposure to sweet substances has been shown to modify the analgesic effect of morphine. Presumably, this modification occurs because such exposure increases the level of endogenous opioids in the brain areas that mediate the analgesic properties of morphine. The present experiments were designed to test whether similar exposure affects morphine's rewarding properties. Both acute (Experiment 1) and chronic (Experiment 2) exposures to sucrose solution were found to enhance the conditioned place preference produced by morphine. Thus, the level of endogenous opioids in brain areas that mediate the rewarding effect of morphine may also be increased by the ingestion of sweet substances.
\end{abstract}

Exposure to sweet substances can alter the analgesic effect produced by morphine. Chronic exposure attenuates the analgesia produced by low doses of morphine. For example, in several studies, rats that had been given continuous access to a sweet solution for a number of days were injected with morphine and then tested on a hot plate. Relative to appropriate controls, these rats had shorter latencies to paw lick (Bergmann, Lieblich, Cohen, \& Ganchrow, 1985; Cohen, Lieblich, \& Bergmann, 1984; Holder, 1988; Lieblich, Cohen, Ganchrow, Blass, \& Bergmann, 1983), which indicates a decrease in the analgesic effect of morphine. In contrast to the attenuation produced by a chronic exposure lasting $48 \mathrm{~h}$ or more, an acute exposure of $26 \mathrm{~h}$ to a sweet solution enhances the analgesia produced by morphine (Holder, 1988). These findings suggest that ingestion of sweet substances increases endogenous opioid levels (e.g., Lieblich et al., 1983 ) in brain areas that mediate the analgesic effect of exogenously administered opiates. Presumably, chronic exposure to a sweet substance produces a chronically elevated level of endogenous opioid that eventually results in cross-tolerance to the analgesic effect of morphine. After an acute exposure, however, morphine has an enhanced effect because it is augmented by the increase in endogenous opioid level.

In addition to analgesia, another prominent property of morphine is its rewarding effect. Animals and human beings self-administer morphine (Griffiths, Bigelow, \& Henningfield, 1980); in addition, rats show a conditioned preference for a place associated with morphine (Sherman, Pickman, Rice, Liebeskind, \& Holman, 1980). It

This research was supported in part by Grant A0681 from the Natural Science and Engineering Research Council of Canada. I thank Mark Holder for suggesting that exposure to sweet water might change the rewarding effect of morphine. Sam Revusky read this paper and made many helpful comments. I am also indebted to Ann Dawe for her skillful and meticulous technical assistance. Correspondence should be addressed to Bow Tong Lett, Department of Psychology, Memorial University of Newfoundland, St. John's, Newfoundland, A1B 3X9 Canada. seems possible that ingestion of sweet substances would interact with the rewarding effect produced by morphine.

\section{EXPERIMENT 1}

Since an acute exposure to a sweet solution enhances morphine's analgesic effect (Holder, 1988), Experiment 1 was designed to determine if such an exposure would enhance morphine's rewarding effect as measured by the technique of conditioned place preference (CPP). To induce CPP, each animal was repeatedly confined in a distinctive chamber while under the influence of morphine. The rats in the experimental group had access to a sweet solution for $30 \mathrm{~min}$ prior to each place-drug pairing, whereas the control rats received water. Similar access was also given prior to the CPP test. The sweet water was not available during the place-drug pairings, and thus should not directly induce any conditioning of place preference. However, if ingestion of a sweet substance increases the endogenous opioid level in brain areas that mediate the rewarding effect of morphine, exposure to sweet water during CPP training and testing should result in facilitation of CPP.

\section{Method}

Subjects. The subjects were 30 male Sprague-Dawley rats with a mean body weight of $333 \mathrm{~g}$ obtained from Canadian Hybrid Farms in Centreville, Nova Scotia. They were maintained under natural lighting augmented by artificial lighting between $8 \mathrm{a} . \mathrm{m}$. and $6 \mathrm{p} . \mathrm{m}$. Experimental procedures were administered between 1 p.m. and 4 p.m. The rats were housed in a standard rack of metal cages. Food was available continuously in the home cage.

Apparatus and Materials. CPP training and testing took place in a shuttlebox consisting of a black chamber $(33 \times 12.5 \times 15 \mathrm{~cm})$ with a wire mesh floor and an adjoining white chamber of the same size with a wood floor. The walls of each chamber were made of painted wood, and each chamber was covered by a clear plastic lid. A removable metal partition was used to confine the rat to a particular side of the shuttlebox during training.

The drug used to induce CPP was morphine sulfate dissolved in isotonic saline $(1 \mathrm{mg} / \mathrm{ml})$. Morphine was injected subcutaneously 
at a dose of $1 \mathrm{mg} / \mathrm{kg}$. The sweet solution was made by dissolving $10 \mathrm{~g}$ of sucrose and $.1 \mathrm{~g}$ of saccharin in each $100 \mathrm{ml}$ of water.

Procedure. The rats were assigned to either Group Sweet, Group Water, or Group Base. The groups were composed of 10 rats each and were equated for mean body weight. First, all the rats in Group Sweet and half of those in Group Base were familiarized with the sweet water to reduce neophobic tendencies. During the 3 days prior to the start of CPP training, these rats were adjusted to a drinking schedule that restricted fluid intake to $30 \mathrm{~min}$ of daily access to sweet water. The remaining rats received similar access to unflavored water.

On each of 3 CPP training days, each separated by a day, the rats were first allowed to drink for $30 \mathrm{~min}$ in the home cage. Group Sweet was given sweet water; Group Water received unflavored water; and the rats in Group Base previously familiarized with sweet water were given sweet water while the remainder received unflavored water. Each rat in Groups Sweet and Water was then taken from its home cage, injected with morphine, and immediately placed in the white chamber of the shuttlebox for $30 \mathrm{~min}$. On these occasions, Group Base received unpaired exposures to the white chamber and morphine. These rats were not injected prior to, or immediately after, placement in the white chamber; instead, the morphine injection was delayed until at least 30 min after the animal was returned to its home cage. Thus, the role of Group Base was to provide a baseline against which to measure CPP in the other two groups.

On the days between place-drug pairings, all rats were simply exposed to the black chamber for $30 \mathrm{~min}$. Prior to placement in the black chamber, each rat was allowed to drink water for $30 \mathrm{~min}$ in the home cage. There were two such exposures and no injections were given.

The rats were tested several days after the last place-drug pairing. During this interim period, all rats received $30 \mathrm{~min}$ of access to water each day. Immediately prior to the test, each rat was given $30 \mathrm{~min}$ of access to either sweet or unflavored water as appropriate. During the test, the partition separating the black and white compartments of the shuttlebox was removed to allow free access to both compartments. At the start of the 10 -min test, each rat was placed in the white chamber with its head pointing away from the black chamber. The rat was considered to be in the white chamber until all four of its paws were in the black chamber. Then it was considered to be in the black chamber until all four paws were in the white chamber, and so on. The percentage of time spent in the white chamber was measured; the percentage of time in the black chamber can be obtained by subtracting percentage of time in the white chamber from 100 .

\section{Results}

Table 1 shows the mean percentage of time spent in the white chamber by each group during the CPP test in Experiment 1 . As can be seen, Groups Sweet and Water each spent more than $50 \%$ of the test period in the drugpaired, white chamber $[t(9)=7.80, p<.001 ; t(9)=$ $2.85, p<.05$, respectively], whereas Group Base did

Table 1

Mean Percentage (and SEM) of Time Spent in the Drug-Paired, White Chamber During the CPP Test by Each Group in Experiment 1

\begin{tabular}{lcc}
\hline & \multicolumn{2}{c}{ Percentage of Time } \\
\cline { 2 - 3 } Group & $M$ & $S E M$ \\
\hline Sweet & 69.8 & 2.5 \\
Water & 54.7 & 1.7 \\
Base & 35.5 & 2.1 \\
\hline
\end{tabular}

not. Both Group Sweet and Group Water also spent more time in the white chamber than did Group Base $[t(18)=$ $10.48, p<.001 ; t(18)=7.28, p<.001$, respectively], and hence both groups showed reliable CPP. As predicted, Group Sweet spent more time in the drug-paired, white chamber than did Group Water $[t(18)=4.98, p<.001]$, and thus showed stronger CPP than did Group Water. These findings indicate that ingestion of sweet water enhanced the CPP produced by morphine.

The Group Sweet rats drank more than those given plain water. During the 30-min drinking periods prior to each place-drug pairing, the rats given sweet water drank a mean of $24.4 \mathrm{ml}$, whereas those given plain water drank $20.0 \mathrm{ml}[t(28)=3.78, p<.001]$. During the 30-min period preceding the CPP test, the rats given sweet water drank $25.4 \mathrm{ml}$, whereas those given plain water drank $20.4 \mathrm{ml}[t(28)=3.87, p<.001]$.

Sweet water by itself had no detectable effect on place preference. In Group Base, the five rats that drank sweet water prior to placement in the white chamber spent $35.7 \%$ of the 10 -min test in the white chamber, whereas those that received plain water spent $35.4 \%$ of the test in that chamber.

\section{EXPERIMENT 2}

Experiment 2 was designed to test the effect of chronic exposure to sweet water on the rewarding properties of morphine. As noted above, chronic exposure to sweet water, lasting $48 \mathrm{~h}$ or more, has been shown to attenuate the analgesic effect of morphine (e.g., Holder, 1988; Lieblich et al., 1983). On the hypothesis that ingestion of sweet substances increases endogenous opioid levels, the attenuation of morphine-induced analgesia produced by chronic exposure to sweet water could be explained as an instance of cross-tolerance. By extrapolation, it could be predicted that chronic exposure to sweet water would produce cross-tolerance to the rewarding effect of morphine. However, although it is well established that even a few exposures to morphine produce a detectable degree of tolerance to its analgesic effect (e.g., Cochin \& Kornetsky, 1964), such exposures do not appear to produce tolerance to the rewarding or motivational effect of the drug. For example, Esposito and Kornetsky (1977) have shown that repeated exposures do not attenuate morphine's facilitating effect on self-stimulation. Furthermore, repeated exposures to morphine have been shown to enhance the subsequent efficacy of morphine in producing CPP (Lett, in press). That is, repeated exposures produced sensitization rather than tolerance to the rewarding effect of morphine. Thus, the weight of evidence suggests that chronic exposure to sweet water should enhance the CPP produced by morphine, as did the acute exposure in Experiment 1.

\section{Method}

Subjects. The subjects were 30 male Sprague-Dawley rats with a mean body weight of $197 \mathrm{~g}$ obtained from Canadian Hybrid Farms. They were maintained in the same way as those in Experiment 1 
Table 2

Mean Percentage (and SEM) of Time Spent in the Drug-Paired, White Chamber During the CPP Test by Each Group in Experiment 2

\begin{tabular}{ccc} 
& \multicolumn{2}{c}{ Percentage of Time } \\
\cline { 2 - 3 } Group & $M$ & $S E M$ \\
\hline Sweet & 70.9 & 2.3 \\
Water & 63.5 & 1.8 \\
Base & 30.6 & 2.2 \\
\hline
\end{tabular}

and experimental procedures were administered between 1 p.m. and 4 p.m.

Procedure. As in Experiment 1 , the rats were assigned in equal numbers to Group Sweet, Group Water, or Group Base. The procedure was essentially the same as that used in Experiment 1. The only important difference was that sweet water was available continually in the home cage of all the rats in Group Sweet and for half of those in Group Base for 5 days prior to the start of CPP training and throughout the rest of the experiment. Group Water and the remainder of Group Base received only unflavored water.

As in Experiment 1, Groups Sweet and Water were injected with morphine $(1 \mathrm{mg} / \mathrm{kg})$ and were then placed in the white chamber on 3 training days. On these occasions, as before, Group Base received unpaired exposures to the white chamber and morphine. In addition, all rats were habituated to the black chamber on two occasions. Several days after the last place-drug pairing, the rats were tested as described above. The percentage of time spent in the white chamber was obtained and assessed as in Experiment 1 .

\section{Results}

Table 2 shows the percentage of time spent in the white chamber by Groups Sweet, Water, and Base during the CPP test. As can be seen, the pattern of results was the same as that obtained in Experiment 1. Groups Sweet and Water each spent more than $50 \%$ of the test period in the drug-paired, white chamber $[t(9)=9.17, p<.001 ; t(9)$ $=7.67, p<.001$, respectively], whereas Group Base did not. In addition, both Group Sweet and Group Water spent more time in the white chamber than did Group Base $[t(18)=12.64, p<.001 ; t(9)=11.57, p<.001$, respectivelyl, and hence exhibited reliable CPP. As predicted, Group Sweet showed stronger CPP than did Group Water $[t(18)=2.58, p<.05]$. Thus, chronic exposure to sweet water enhanced the CPP produced by morphine in Experiment 2, as did acute exposure in Experiment 1.

In Group Base, the rats that had received sweet water spent a slightly greater percentage of time in the white chamber during the CPP test than did those that had been given plain water, $32.3 \%$ and $28.2 \%$, respectively. However, this difference was not statistically reliable $[t(18)$ $=1.09, p>.20]$.

\section{DISCUSSION}

Ingestion of sweet water some time prior to placemorphine pairing enhanced CPP in both experiments. Enhancement of CPP was found both when the sweet water was limited to the 30-min period just prior to each placemorphine pairing and the CPP test (Experiment 1), and when sweet water was continually available in the home cage throughout the training and test phases (Experiment 2). According to the generally accepted principles of classical conditioning, the temporal relationship between the sweet water and the place stimulus should have precluded any association between them; indeed, no reliable effect of sweet water alone on place preference was found. In both experiments, the rats in Group Base that had access to sweet water prior to placement in the white chamber showed little difference in place preference compared to those that were given water only. Thus, the enhancement of CPP observed here cannot be explained as simply the addition of a conditioned preference produced by a place-sweet water association to the conditioned preference produced by the place-morphine association.

Sucrose solution is a highly preferred substance and an effective reward; presumably, ingestion of sweet water activates the central reward system. The present findings suggest that one route of activation might involve the release of an endogenous opiate. Although the rewarding effect of the endogenous opiate released by ingesting sweet water would not have been sufficient to produce CPP by itself, it could have summated with, or potentiated, the injected morphine, producing an enhancement of CPP in the present experiments.

Consistent with the notion that ingestion of a sweet substance releases endogenous opiates, acute exposure to sweet water enhances both the analgesic (Holder, 1988) and the rewarding (Experiment 1) effects of morphine. In contrast, chronic exposure produces cross-tolerance to the analgesic (e.g., Bergmann et al., 1985), but not to the rewarding (Experiment 2), effect of the drug. These findings also support the hypothesized relationship between sweet substances and endogenous opiates since, as noted above, repeated morphine exposures produce a similar pattern of findings. That is, repeated exposures to morphine also produce tolerance to its analgesic (e.g., Cochin \& Kornetsky, 1964) effect, but not to its rewarding effect (Esposito \& Kornetsky, 1977; Lett, in press). This difference probably reflects the different sites of action of the two effects. Analgesia is produced by actions at a number of sites, including the periqueductal and periventricular gray matter of the brain stem (Mayer \& Price, 1982), whereas the site of action of the rewarding effect is the ventral tegmental area (Bozarth \& Wise, 1983).

\section{REFERENCES}

Bergmann, F., Lieblich, I., Cohen, E., \& Ganchrow, J. R. (1985). Infiuence of intake of sweet solutions on the analgesic effect of a low dose of morphine in randomly bred rats. Behavioral \& Neural Biology, 44, 347-353.

Bozarth, M. A., \& Wise, R. A. (1983). Neural substrates of opiate reinforcement. Progress in Neuro-Psychopharmacology \& Biological Psychiatry, 7, 569-575.

Cochin, J., \& Kornersky, C. (1964). Development and loss of tolerance to morphine in the rat after single and multiple injections. Journal of Pharmacology \& Experimental Therapeutics, 145, 1-10.

Cohen, E., Lieblich, I., \& BergmanN, F. (1984). Effects of chronically elevated intake of different concentrations of saccharin on mor- 
phine tolerance in genetically selected rats. Physiology \& Behavior, 32, 1041-1043.

Esposito, R., \& KoRnetsky, C. (1977). Morphine lowering of selfstimulation thresholds: Lack of tolerance with long term administration. Science, 195, 189-191.

Griffiths, R. R., Bigelow, G. E., \& Henningfield, J. E. (1980). Similarities in animal and human drug taking behavior. In N. K. Mello (Ed.), Advances in substance abuse: Behavioral and biological research (pp. 1-90). Greenwich, CT: JAI Press.

Holder, M. D. (1988). Responsivity to pain in rats changed by the ingestion of flavored water. Behavioral \& Neural Biology, 49, 45-53.

LETT, B. T. (in press). Repeated exposures increase rather than diminish the rewarding effect of drugs. Psychopharmacology.

lieblich, I., Cohen, E., Ganchrow, J. R., Blass, E. M., \& Berg-
MANN, F. (1983). Morphine tolerance in genetically selected rats induced by chronically elevated saccharin intake. Science, 221, 871-873.

Mayer, D. J., \& Price, D. D. (1982). A physiological and psychological analysis of pain: A potential model of motivation. In $\mathrm{D}$. W. Pfaff (Ed.), The physiological mechanisms of motivation (pp. 433-471). New York: Springer-Verlag.

Sherman, J. E., Pickman, C., Rice, A., Liebeskind, J. C., \& HolMAN, E. W. (1980). Rewarding and aversive effects of morphine: Temporal and pharmacological properties. Pharmacology, Biochemistry \& Behavior, 13, 501-505.

(Manuscript received June 21, 1988; revision accepted for publication February $2,1989$. ) 